\title{
Trying to set up the flavanolic phases during grape seed ripening: A spectral and chemical approach
}

\author{
Natalia Quijada-Morín a , Ignacio García-Estévez a , Julio Nogales-Bueno ${ }^{\mathrm{b}}$, \\ Francisco J. Rodríguez-Pulido ${ }^{\mathrm{b}}$, Francisco J. Heredia ${ }^{\mathrm{b}}$, Julián C. Rivas-Gonzalo ${ }^{\mathrm{a}}$, \\ M. Teresa Escribano-Bailón a , José Miguel Hernández-Hierro ${ }^{\text {b,* }}$ \\ ${ }^{a}$ Grupo de Investigación en Polifenoles, Unidad de Nutrición y Bromatología, Facultad de Farmacia, University of Salamanca, Campus Miguel de Unamuno, \\ Salamanca, E 37007 Spain \\ ${ }^{\mathrm{b}}$ Food Colour \& Quality Laboratory, Department of Nutrition \& Food Science, Universidad de Sevilla, Facultad de Farmacia, Sevilla, 41012 Spain
}

\section{A R T I C L E I N F O}

\section{Article history:}

Received 7 June 2016

Received in revised form

26 July 2016

Accepted 30 July 2016

Available online 30 July 2016

Keywords:

Grape seeds

Hyperspectral image

Proanthocyanidins

HPLC-MS

Phloroglucinolysis

\begin{abstract}
A B S T R A C T
Grape seeds were collected in ten different dates and classified in seven groups according to their individual hyperspectral imaging characteristics.

Proanthocyanidin composition was studied using HPLC-MS for oligomers and acid catalyzed cleavage for polymers characterization. The combination of both analysis provided a complete description of the flavanols. Chemometric analysis was performed to summarize the analytical results. None of the considered variables presented statistical differences among all groups. From one to five groups were found for each variable, while three was the most frequent value, consequently three putative stages might be considered the real number of different analytical stages since it is the number of statistically significant groups for the majority of the compounds. This classification could be considered as the first step to optimize the use of seeds in winemaking to minimize the gap between sugar and phenolic maturities, consequence of the global climate change, mainly observed in warm climate.
\end{abstract}

(c) 2016 Elsevier B.V. All rights reserved.

\section{Introduction}

Phenolic compounds in grapes are mainly found in seeds and skins. Proanthocyanidins are present in both tissues, but differences in their composition have been reported as a function of the tissue they are found in. In grape skins both procyanidins and prodelphinidins are present but in seeds only procyanidins have been described [1-3]. Moreover, seeds proanthocyanidins present lower polymerization degree and higher galloylation degree than skins proanthocyanidins. These compounds are involved in wine stability, organoleptic properties such as color or astringency and other properties such as antioxidant activity.

Grape phenolic composition is well known to evolve during ripening, and it is important to take this into account in order to choose the optimum vintage moment. The term "phenolic maturity" was been proposed by Glories and Augustin [4] to describe the concentration of phenolic compounds in grapes, both skins and seeds, and the ease with which they are released. As stated above, phenolic compounds are highly related to organoleptic properties of wines and thus, to its quality.

\footnotetext{
* Corresponding author.

E-mail address: jmhhierro@us.es (J.M. Hernández-Hierro).
}

Moreover, grape maturity presents some heterogeneity among different plants of the same field and even in different grapes of the same plant or bunch, which makes difficult to choose the optimum vintage moment $[5,6]$. During the last years, the span between phenolic maturity and sugar maturity in grapes is increasing due to global climate change [7], primarily in warm areas. The lack of balance among the phenolic and sugar maturities leads to a decrease of the wine quality and stability. This situation causes a great concern among winemakers, and several strategies has been proposed in order to maintain the wine quality despite the span between technological and phenolic maturities. Among the strategies developed to mitigate the new situation different winemaking techniques, such as seed removal or the addition of seeds from over-ripen grapes, can be performed to reduce the negative effects of the abovementioned maturity gap.

Berry development consists of three phases: two successive sigmoidal growth periods separated by a lag phase [8]. The first period of growth lasts from bloom to approximately 60 days afterward, being characterized by a rapid increase in the berry volume and seeds almost fully grown. Phase II is characterized by a decrease in the growth rate. Finally, phase III, is the ripening stage and it is characterized by the second period of berry growth, when sugars are rapidly accumulated.

According to Kennedy and coworkers [9], grape seed 
proanthocyanidins biosynthesis and accumulation commenced with seed development. They reach their maximum at the beginning of veraison or 1 week after veraison. They suffer a sharply decrease in the first weeks after veraison [10] and they tend to decrease slightly until over-ripening $[10,11]$. For obtaining high quality red wines, it is important to achieve a good level of proanthocyanidins since it is well known that red wines with high content of proanthocyanins tend to age better than those with lower proanthocyanin content. In young red wines, these compounds are involved in color stabilization by copigmentation reactions [12] and further in the formation of anthocyanins derived compounds [13]. On the other hand, seed proanthocyanidins are also involved in wine astringency development, and their maturity level is important since less mature grape seeds are more astringent and present higher tannic intensity [11].

It is well known that seed grape coloration changes during maturity from green to yellow and finally to brown-grey hues. These changes in seed coat color have been related to developmental changes in berry [10] and can be used as an indicator of berry ripeness.

During grape ripening, seeds undergo several compositional and physical changes, which modify the amount and distribution of extracted flavan-3-ols. The integument is intensively lignified and dehydrated, leading to seed hardening and to a more difficult release of flavanols [10]. Total amount of flavanols present in grape seeds suffers a decrease as ripens progresses [14], and their extractability is also reduced as a result of a higher interaction with cellular components [15] as well as the development of several compositional changes, such as oxidative cross-linking, that would be also related to a lesser extractability [9]. These changes lead to diminish the total amount of proanthocyanidins extracted during winemaking.

Hyperspectral imaging is an emerging and green chemistry technique for non-destructive and rapid food analysis usually carried out in either the visible-short near infrared (vis-NIR; 400$1000 \mathrm{~nm}$ ) or near infrared (NIR; 1000-1700 nm) spectral regions [16]. Winemakers are continuously looking for high quality wines and the major factors impacting on wine quality are related to winemaking process and cultivar features. Among others, grape variety, maturity or sugar content are typically analyzed in order to determine grape quality, set grape price and classify grapes for a range of produced wines [17].

The aim of this work is to evaluate the potential of the imaging hyperspectral techniques to differentiate ripening stages in seeds, based on the flavanol composition. To do this, the possible relationship between the homogeneous groups of seeds formed based on the hyperspectral imaging characteristics and the phenolic composition was studied. The differentiation of ripening stages in seeds according to its flavanolic composition could be used to improve the selection of the seeds used for upgrade wine characteristics, providing a non-destructive, fast method for seeds classification. This classification would be the first step of an extended study which would lead with the use of the classified seeds in vinifications with lack of phenolic maturity in order to evaluate which of the groups of seeds would provide better characteristics to the treated wines.

\section{Materials and methods}

\subsection{Grape seed samples}

Vitis vinifera L. cv. Tempranillo samples were collected from a vineyard located in the Condado de Huelva Designation of Origin (D.O.) (Andalusia, Spain) which is under the typical climatic conditions of a warm area [18]. The aforesaid cultivar is the most often grown red grape cultivar in Spain for producing quality red wines. Red grapes were collected at different physiological stages during berry maturity in the 2013 vintage: prior to veraison (July $2^{\text {nd }}$ ) to over-ripening (August $12^{\text {th }}$ ). Ten dates were taken into account for the aforesaid cultivar. Grape seeds were then separated manually from the whole grapes and were immediately frozen and stored at $-20{ }^{\circ} \mathrm{C}$ until analyses were performed. Prior to the hyperspectral analyses, whole seeds from the ten dates were manually merged into a single sample. Grape maturity presents some heterogeneity among different plants of the same field and even in different grapes of the same plant or bunch. Taking into the account the foresaid heterogeneity, it is desirable to create hyperspectral homogeneous groups, which would be set up regarding the whole composition and not only the phenolic composition. After that, the possible relationship between the homogeneous groups of seeds formed based on the hyperspectral imaging characteristics and the phenolic composition could be studied and putative stages might be considered.

\subsection{Near infrared hyperspectral imaging analysis}

Equipment and procedure used to image recording are described in detail elsewhere in Rodríguez-Pulido et al. [19]. Briefly, hyperspectral imaging device (Infaimon S.L., Barcelona, Spain) comprised a Xenics ${ }^{B}$ XEVA-USB InGaAs camera $(320 \times 256$ pixels; Xenics Infrared Solutions, Inc., Leuven, Belgium), a spectrograph (Specim ImSpector N17E Enhanced; Spectral Imaging Ltd., Oulu, Finland) covering the spectral range between 900 and $1700 \mathrm{~nm}$ (spectral resolution of $3.25 \mathrm{~nm}$ ). The images were recorded using the abovementioned mirror scanner pushbroom device, a $50 \mathrm{~Hz}$ frame rate, an exposure time of $9 \mathrm{~ms}$ and the instrument acquisition software SpectralDAQ v. 3.62 (Spectral Imaging Ltd., Oulu, Finland). The whole grape seed samples were thawed and tempered at room temperature and hyperspectral image of sets of 48 individual seeds were recorded. The maximum number of grape seed per image is restricted due to the limitation in the measurement area. Grape seed samples were randomly selected just for hyperspectral measurement. A total of 26 images (one of them contains 32 individual seeds) were recorded. After calibration and segmentation processes, individual spectrum of each grape seed was obtained using Matlab (R2010b; The Math Works, Inc., USA). Noisy wavebands at both extremes of the spectra range were removed and only spectral data in the resulting effective wavelength $950-1650 \mathrm{~nm}$ regions were used in data analysis due to reduced efficiency outside this range in the used device. These procedures lead to the obtaining of 1232 grape seed spectra, which were combined into the spectral matrix $X(X=1232$ samples $\times \log (1 / R)$ units at 215 wavelengths).

\subsection{Chemometrical methods}

An unsupervised pattern recognition technique, principal component analysis (PCA), was used in order to provide information about the latent structure of spectral matrix and to find spectral differences among all spectral samples. This method provides information related to spectral outliers (H outliers) and the distribution of samples in the newly-created space. The software used for PCA analysis and spectral pretreatment was Win ISI ${ }^{\text {i. }}$ (v1.50) (Infrasoft International, LLC, Port Matilda, PA, USA). The k-means clustering algorithm was also used. Given a fixed number of (desired or hypothesized) $\mathrm{k}$ clusters, assign observations to those clusters so that the means across clusters (for all variables) are as different from each other as possible. The software used for the aforementioned analysis was STATISTICA 8.0 (StatSoft Inc, Tulsa, OK, USA). Canonical Biplot is a method of multivariate analysis similar to MANOVA (Multivariate Analysis of Variance) 
that permits simultaneous plots of the different groups to be compared and the different variables under analysis to be obtained, but with the intrinsic characteristics of Biplot methods. It has been proposed confidence circles based on univariate Student's $t$-tests to perform post-hoc analyses of each variable, the projections of the circles onto the direction representing a variable close to a confidence interval. Checking the overlapping of two projections allows the significance of the difference between groups over a particular variable to be established. The plane provides a global idea about the differences between groups in all variables. The software used for the aforesaid analysis was Multbiplot [20].

\subsection{Phenolic compounds extraction}

After imaging processing, seeds were freeze dried and flavanolic compounds were extracted following the procedure described elsewhere [11], briefly $500 \mathrm{mg}$ of ground seeds were extracted with $10 \mathrm{~mL}$ of a mixture of methanol: water 3:1; they were homogenized using a Polytron for $1 \mathrm{~min}$ and sonicated for $15 \mathrm{~min}$. Afterward, they were centrifuged for $10 \mathrm{~min}$ at 10,000 r.p.m. Supernatant were retired and the extraction procedure was repeated twice more. Supernatants were pooled together and concentrated at low pressure and made up to a final volume of $5 \mathrm{~mL}$ of aqueous extract.

\subsection{Chemical analysis}

\subsubsection{Acid cleavage in the presence of phloroglucinol}

The acid cleavage in the presence of phloroglucinol was carried out as previously described [21] with slight differences due to the samples nature. $300 \mu \mathrm{L}$ of aqueous seed extract was loaded on a mixed-mode anion exchange/reverse phase SPE cartridge Oasis MAX from Waters. The cartridge was previously conditioned with $2 \mathrm{~mL}$ of $75 \%$ acetone followed by $4 \mathrm{~mL}$ of water. After washing with $4 \mathrm{~mL}$ of water, the flavanolic extract was eluted with $8 \mathrm{~mL}$ of acetone $75 \%$. Eluate was brought to dryness using a rotary evaporator at $30{ }^{\circ} \mathrm{C}$ and then redisolved using $900 \mu \mathrm{L}$ of methanol in order to obtain the methanolic proanthocyanidic seed extract. The cleavage reagent was prepared by dissolving $100 \mathrm{mg} \mathrm{L}^{-1}$ of phloroglucinol and $10 \mathrm{mg} \mathrm{L}^{-1}$ of ascorbic acid in acidic methanol $(0.1 \mathrm{M} \mathrm{HCl}) .100 \mu \mathrm{L}$ of the methanolic seed extract was mixed with $200 \mu \mathrm{L}$ of cleavage reagent and submitted to acid cleavage at $50{ }^{\circ} \mathrm{C}$ for $45 \mathrm{~min}$. Afterward the reaction was stopped by cooling and the excess of reactive was quenched by the addition of $2.7 \mathrm{~mL}$ of sodium acetate $15 \mathrm{mM}$ aqueous solution. The reaction mixture was purified by SPE using an Oasis MAX cartridge (60 mg, $3 \mathrm{~mL}$ ) in the same conditions previously described to obtain the methanolic extract. The eluate was dissolved in ultrapure water and submitted to HPLC-DAD analysis in the conditions described elsewhere [21].

\subsubsection{HPLC-DAD-MS quantification of proanthocyanidin oligomers}

Proanthocyanidin oligomers analysis were carried out using a Hewlett-Packard 1200 series liquid chromatograph, equipped with an autosampler, a thermostatted column department, a quaternary pump, a vacuum degasser and a diode array detector (DAD) coupled to an API 3200 Qtrap mass spectrometer equipped with an ESI source and a triple-quadrupole linear ion trap mass analyzer that was controlled by Analyst 5.1 software (Applied Biosystems, Darmstadt, Germany).

The chromatographic separation was performed on an Agilent Poroshell-120 $5.6 \mathrm{~mm} \times 150 \mathrm{~mm}, 2.7 \mu \mathrm{m}$ column, thermostated at $25{ }^{\circ} \mathrm{C}$; the mobile phases were aqueous formic acid $0.1 \%(\mathrm{~A})$ and acetonitrile (B). The elution profile was as follows: $0-10 \%$ of B in $5 \mathrm{~min}, 10-14.5 \%$ in $35 \mathrm{~min}$, followed by the washing and restabilizing of the column to initial conditions. The flow rate was set at $0.5 \mathrm{~mL} \mathrm{~min}{ }^{-1}$ and the injection volume was $100 \mu \mathrm{L}$. MS detection was carried out in the positive mode, using multiple reaction monitoring (MRM) analysis under the following conditions: Ion spray voltage (IS) $5500 \mathrm{~V}$, Temperature $300^{\circ} \mathrm{C}$, curtain gas (CUR) 20 psi, collision gas (CAD) 3 psi, nebulizer gas (GS1) $30 \mathrm{psi}$, heater gas (GS2) $40 \mathrm{psi}$, declustering potential (DP) $70 \mathrm{~V}$, entrance potential (EP) $10 \mathrm{~V}$, variable collision energy (CE) $22 \mathrm{~V} /$ $32 \mathrm{~V}$, Collision cell exit potential (CXP) $3 \mathrm{~V}$. Nitrogen served as the curtain and collision gas, while Zero grade air was used as the nebulizer and turbo gas. The quadrupoles were set at Unit resolution.

For sample preparation, $200 \mu \mathrm{L}$ of the aqueous seed extract were mixed with $385 \mu \mathrm{L}$ of ultrapure water and $15 \mu \mathrm{L}$ of chlorogenic acid which was used as internal standard for MS quantification, filtered by $0.45 \mu \mathrm{m}$ and analyzed.

All the analyses were performed in triplicate.

\section{Results and discussion}

\subsection{Near infrared data analysis}

A standard normal variate (SNV) and second derivative spectral pre-treatment $(2,5,5,1)$ was applied. Mathematical treatment is denoted as a,b,c,d, where the first digit is the number of the derivative; the second is the gap over which the derivative is calculated; the third is the number of data points in a running average or smoothing, and the fourth is the second smoothing [22]. Principal component analysis (PCA) was applied to reduce the dimension of the aforementioned spectral matrix. Overall, the spectral variability explained was $90.43 \%$ using 14 principal components. Mahalanobis distances ( $\mathrm{H}$ values) for each sample were also calculated and 10 outliers $(\mathrm{H}>3)$ were found and removed. Fig. 1a shows the grape seeds $(\mathrm{N}=1222)$ spectra over the 950 $1650 \mathrm{~nm}$ spectral range. The remaining samples were allocated into seven predefined groups using by the k-means clustering algorithm using the aforementioned PCA scores. The aforesaid number of groups had been experimentally proposed in a previous study [23] taking into account CIELAB coordinates from RGB color space in similar samples and was set in our study for the k-means clustering analysis taking into account this bibliographic information. The new seven homogenous groups, created taking into account hyperspectral measurements, were used in all the subsequent chemical or chemometric analyses. Fig. 1b shows the average spectrum of each hyperspectral created groups over the 950-1650 nm range.

\subsection{Proanthocyanidin composition}

Proanthocyanidin analysis is a difficult task due to the great variety of compounds that form this family and to the high similarity level between them. Several analytical procedures had been developed in order to give an accurate composition of these compounds. Acid catalyzed cleavage in the presence of phloroglucinol has been proved as an interesting procedure to analyze large proanthocyanidins [24]. This analytical tool provides several interesting characteristics of the proanthocyanidins analyzed, such as their average polymerization degree, or their subunit composition. On the other hand, this kind of analysis does not provide information about the relative amount of each compound present in the samples. Table 1 summarizes the results obtained from the acid cleavage in the presence of phloroglucinol of the seven groups of seeds created after the hyperspectral measurements.

The total amount of proanthocyanidins in the studied samples ranged from 23.18 to $50.20 \mathrm{mg}$ per gram of freezed dried seed.

As previously reported for grape seeds, catechin, epicatechin 

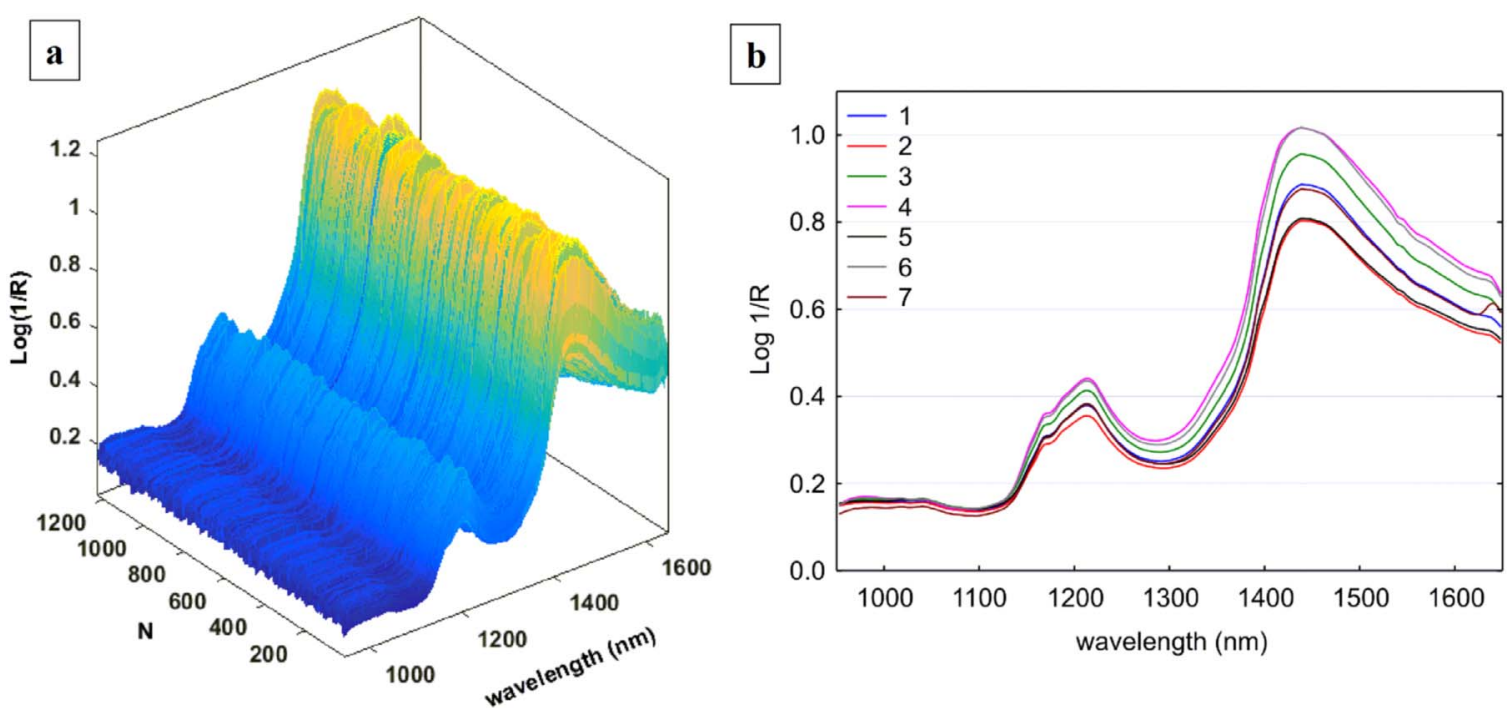

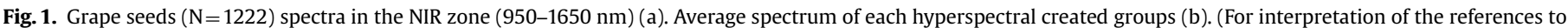
color in this figure, the reader is referred to the web version of this article.)

Table 1

Composition and characteristics of grape seeds proanthocyanidins.

\begin{tabular}{|c|c|c|c|c|c|c|c|c|}
\hline \multirow[b]{2}{*}{ Sample } & \multirow[b]{2}{*}{$\mathrm{aDP}$} & \multirow[b]{2}{*}{ Concentration $\left(\mathrm{mg} \mathrm{g}^{-1}\right)$} & \multicolumn{3}{|c|}{ Extension subunits } & \multicolumn{3}{|c|}{ Terminal subunits } \\
\hline & & & \%Cat & \%EC & \%EC g & \%Cat & \%EC & \%EC g \\
\hline 1 & $3.67 \pm 0.36^{a b}$ & $45.47 \pm 6.18^{a}$ & $16.97 \pm 1.05^{b c}$ & $55.47 \pm 2.62^{a b}$ & $0.14 \pm 0.12^{a}$ & $18.55 \pm 1.63^{a b}$ & $6.83 \pm 0.46^{b c}$ & $2.02 \pm 0.84^{a}$ \\
\hline 2 & $2.76 \pm 0.33^{c}$ & $24.79 \pm 7.37 b c$ & $18.86 \pm 1.22^{b c}$ & $44.55 \pm 4.82^{c}$ & n.d. & $23.83 \pm 2.87^{a}$ & $11.56 \pm 1.02^{a}$ & $1.20 \pm 0.85^{a}$ \\
\hline 3 & $4.34 \pm 0.08^{a}$ & $47.84 \pm 4.89^{a}$ & $19.29 \pm 1.33^{b c}$ & $57.54 \pm 1.83^{a}$ & $0.13 \pm 0.10^{a}$ & $17.1 \pm 0.54^{b}$ & $5.35 \pm 0.38^{c}$ & $0.60 \pm 0.35^{a}$ \\
\hline 4 & $3.24 \pm 0.36^{b c}$ & $40.61 \pm 4.94 a b$ & $14.82 \pm 0.58^{c}$ & $54.01 \pm 3.05^{a b}$ & $0.01 \pm 3.95 \mathrm{E}-03^{a}$ & $23.35 \pm 2.22^{a}$ & $6.50 \pm 1.00^{c}$ & $1.31 \pm 0.39^{a}$ \\
\hline 5 & $3.26 \pm 0.42^{b c}$ & $23.68 \pm 7.38^{c}$ & $21.32 \pm 2.28^{a b}$ & $47.65 \pm 2.86^{b c}$ & n.d. & $20.68 \pm 3.44{ }^{a b}$ & $9.54 \pm 1.49^{a b}$ & $0.81 \pm 1.03^{a}$ \\
\hline 6 & $3.89 \pm 0.20^{a b}$ & $50.21 \pm 4.43^{a}$ & $16.33 \pm 0.18^{b c}$ & $57.82 \pm 1.55^{a}$ & $0.08 \pm 0.11^{a}$ & $18.21 \pm 1.16^{a b}$ & $5.43 \pm 0.34^{c}$ & $2.13 \pm 0.96^{a}$ \\
\hline 7 & $3.8 \pm 0.366^{a b}$ & $23.18 \pm 6.34^{c}$ & $25.82 \pm 3.91^{a}$ & $47.74 \pm 3.09 b c$ & n.d. & $18.92 \pm 0.44^{a b}$ & $6.14 \pm 1.62^{c}$ & $1.39 \pm 1.96{ }^{a}$ \\
\hline
\end{tabular}

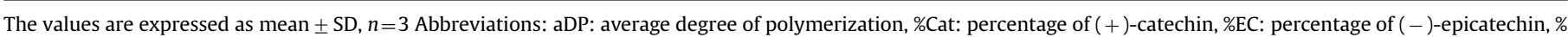
EC g: percentage of ( - )-epicatechin-gallate, n.d.: non-detected. Different letters indicate significant differences ( $\mathrm{p}<0.05$; Tukey test) between samples.

and epicatechin gallate were detected in both terminal and extension positions [3,14,25], nevertheless, epicatechin gallate was detected in all samples in terminal position while only in four of them was also found in extension position.

As can be seen in Table 1, epicatechin was the most abundant subunit in extension positions, and catechin was the most abundant one in terminal positions, as previously described by other authors for grape seeds [3,26]. Epicatechin gallate was the less abundant subunit in both positions, representing less than $2.13 \%$ in terminal position. This percentage is lower than the previously reported for Tempranillo grape seeds by other authors, which have reported levels up to $2.5 \%$ in terminal and $11.8 \%$ in extension positions [27]. In our study, only four samples presented epicatechin gallate in extension positions. The low percentage found in the studied samples could indicate that other factors other than grape variety, such as climatic conditions, water status may have an important influence in the percentage of galloylation found in seeds. Moreover, the percentage of galloyllation varies as ripens progress but differences are found depending on the cultivar studied, Bordiga and coworkers [26] have reported a decrease in the galloyllation degree of seeds as ripens progressed for Nebbiolo and Pinot bianco varieties, while they found a decrease followed by an increase for Cabernet Sauvignon, Moscato bianco and Nascetta and levels almost constant for Malvasia bianca. This nonhomogeneous variation also makes difficult to relate the galloylation degree of seeds to a maturity stage.

aDP ranged from $2.76 \pm 0.33$ to $4.34 \pm 0.08$. This result is quite lower than the previously described by other authors for
Tempranillo grape seeds at maturity [27], nevertheless, a great variation for grape seed polymerization degree has been described in literature, among varieties but also vintages or terroirs [14,28]. aDP of seeds proanthocyanidins as ripens progress also seems to be related to the grape variety since some authors have describe a decrease followed by an increase for Cabernet Sauvignon and Carmenere [25], and for Cabernet Sauvignon, Malvasia bianca and Nascetta [26], while they also reported a decrease for Moscato bianco, Nebbiolo and Pinot bianco. Other authors reported only a slight variation for Pinot noir and Cabernet sauvignon [29]. Different aDP evolution among vintages have been also described [14]. As in the case of galloylation, the different behaviors described make a difficult task to relate aDP to grape seed maturity stage.

\subsection{Proanthocyanidin oligomers composition}

Up to 76 different compounds were detected and quantified using the described HPLC-MS method, 3 monomers,7 dimers, 8 trimers, 11 tetramers, 9 pentamers, 6 monogalloylated dimers, 8 monogalloylated trimers, 9 monogalloylated tetramers, 6 monogalloylated pentamers and 9 digalloylated compounds (see Supplementary Table). Digalloylated compounds were detected in all samples using this analytical tool, which reveals itself as more accurate than depolymerization in the presence of phloroglucinol for small compounds with galloylated subunits, since epicatechin gallate in extension positions could only be detected and quantified followed to phloroglucinolysis when these compounds 


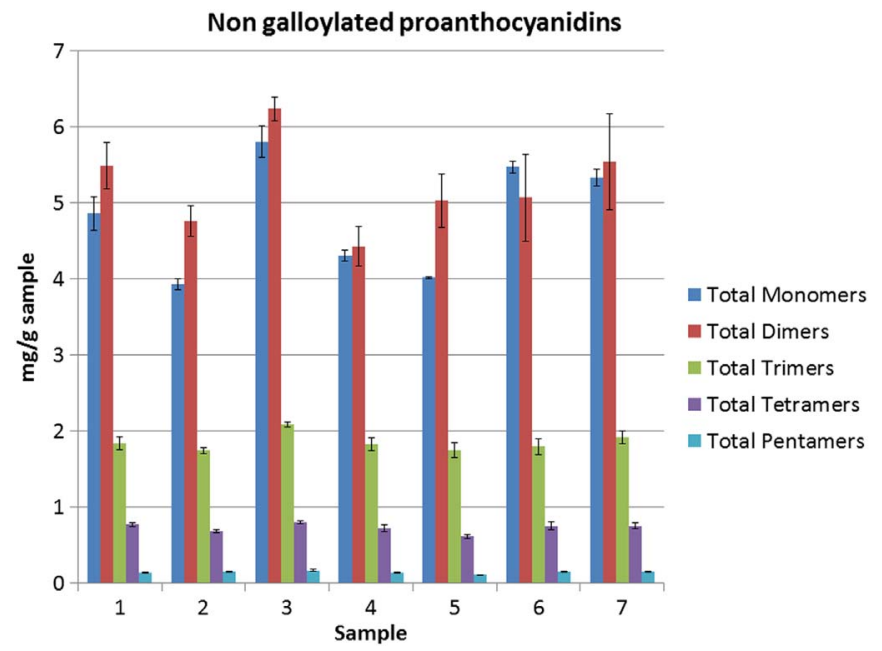

Fig. 2. Non galloylated proanthocyanidin contents in the seven groups of seeds grouped as a function of their polymerization degree.

reached a higher concentration in the samples, despite the differences found in the total amount of these compounds were very low.

As can be seen in Fig. 2, dimers were the most abundant compounds in six of the seven groups of seeds, while monomers were the most abundant compounds in one of them. Trimers, tetramers and pentamers presented similar levels in all the groups of seeds. Regarding galloylated compounds (Fig. 3), they represented from $8 \%$ to $13 \%$ of the quantified compounds. Galloylated dimers were the most abundant compounds in all the groups of seeds $61-66 \%$ of the galloylated compounds), followed by monomers and galloylated tetramers. Digalloylated compounds and monogalloylated trimers present a quite lower concentration, similar among them while the less abundant compounds were galloylated pentamers which represented around $1 \%$ of galloylated compounds.

The total amount of compounds quantified using this method ranged from $12.42 \mathrm{mg} \mathrm{g}^{-1}$ to $16.77 \mathrm{mg} \mathrm{g}^{-1}$ which represents 29.6$52.9 \%$ of the amount in weight determined by acid cleavage in the presence of phloroglucinol which involved all the proanthocyanidins present in the sample, which supposes a good estimation of the composition of proanthocyanidins compounds in the samples.

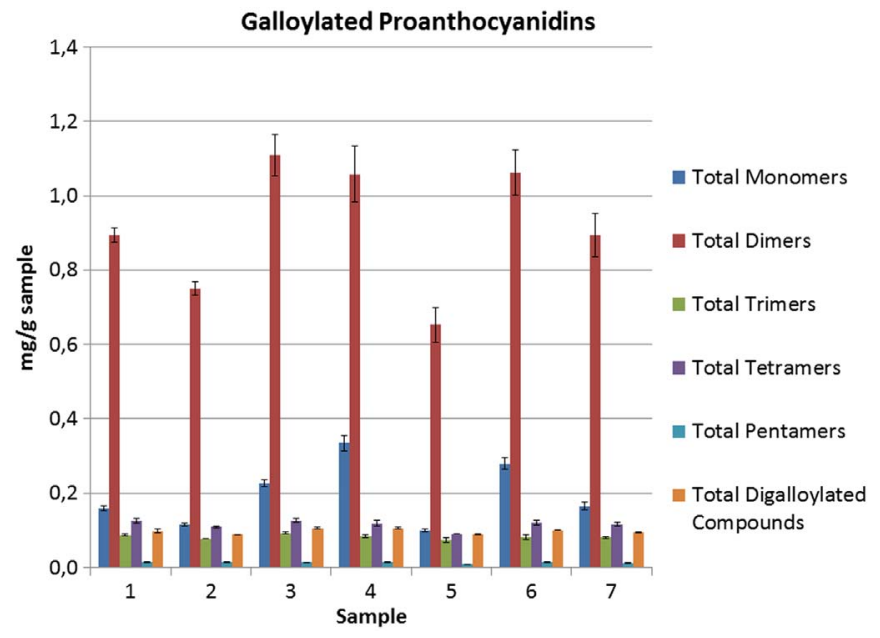

Fig. 3. Galloylated proanthocyanidin contents in the seven groups of seeds grouped as a function of their polymerization degree.

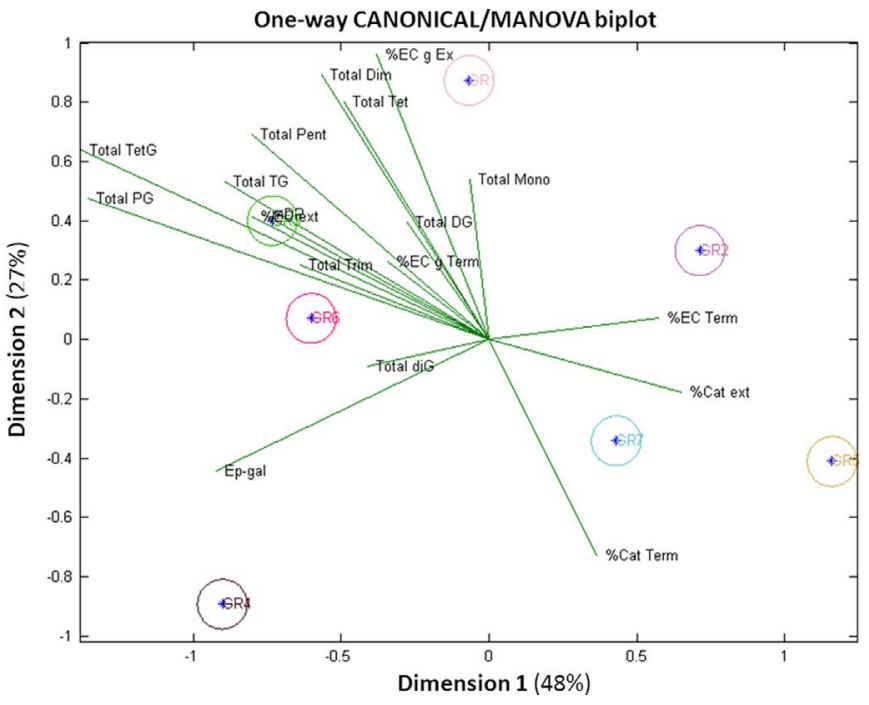

Fig. 4. Canonical Biplot/MANOVA plot.

\subsection{Chemical data analysis}

Chemometric analysis of the obtained compositional data has been performed using Canonical Biplot/MANOVA method in order to summarize the above discussed chemical results. The number of variables which presents significant differences between all the proposed seven groups is null as can be inferred from Fig. 4. Actually, the number of obtained groups in the post-hoc tests ranged from 5 to a single one depending on the analyzed compound. The compounds that present the highest number of groups are total monomers and epicatechin gallate. Furthermore, the most repeated number of groups is three and therefore it may be considered that the real number of analytical stages might be close to this number for the majority of analyzed compounds. This indicates that despite seven groups of seeds were successfully differentiated using hyperspectral techniques, their flavanolic composition is not statistically different enough to stablish seven groups with specific composition characteristics, and only three can be actually considered.

\section{Conclusions}

Near infrared hyperspectral analysis is revealed as interesting tools in order to classify grape seeds according to several chemical characteristics providing homogenous groups that could be analyzed in order to find more representative values for each sample. The combination of oligomers analysis and depolymerization in the presence of phloroglucinol provided a deep knowledge of the composition of the proanthocyanidins present in grape seeds. However, the number of groups that has been proposed using hyperspectral analysis does not match with the putative flavanolic stages. In a preliminary way, three flavanolic stages might be considered the real number of analytical stages since it is the number of statistically significant groups for the majority of the analyzed compounds. These results point out the difficulties to establish clear different groups of seeds according to their flavanolic composition, and thus the implications this has in order to select the optimum harvest date or to classify the seeds that could be used as a source of proanthocyanidins during winemaking. Further studies should be done in order to determine the ability of each one of the three putatives groups of seeds obtained in this study to minimize organoleptic problems caused by the lack of phenolic maturity in grapes. Nonetheless, a comprehensive study 
should be made in order to evaluate several abiotic factors, including vintage, watering, sun exposure, vine age, soil, ripening, etc. to ascertain the most significant stages regarding their flavanolic composition.

\section{Acknowledgements}

Thanks are due to the Spanish MINECO (Project ref. AGL201458486-C02, co-financed with FEDER) and J. Nogales-Bueno thanks the Spanish MINECO for FPI grant (BES-2012-060192).

\section{Appendix A. Supplementary material}

Supplementary data associated with this article can be found in the online version at doi:10.1016/j.talanta.2016.07.064.

\section{References}

[1] M.T. Escribano Bailón, M.T. Guerra, J.C. Rivas Gonzalo, C. Santos Buelga, Proanthocyanidin composition in skin and seed from grapes, Polyphenols 94 (69) (1995) 225-226.

[2] M.T. Escribano-Bailon, Y. Gutiérrez-Fernandez, J.C. Rivas-Gonzalo, C. SantosBuelga, Characterization of procyanidins of Vitis vinifera variety Tinta del País grape seeds, J. Agric. Food Chem. 40 (1992) 1794-1799.

[3] R.L. Hanlin, M.A. Kelm, K.L. Wilkinson, M.O. Downey, Detailed Characterization of Proanthocyanidins in Skin, Seeds, and Wine of Shiraz and Cabernet Sauvignon Wine Grapes (Vitis vinifera), J. Agric. Food Chem. 59 (2011) 13265-13276.

[4] Y. Glories, M. Augustin, Maturité phénolique du raisin, conséquences technologiques: applications aux millésimes 1991 et 1992. In: Proceedings of the Actes du Colloque Journée tecnique du CIVB, (Bordeaux, 1993), pp. 26-61.

[5] J.M. Cortell, M. Halbleib, A.V. Gallagher, T.L. Righetti, J.A. Kennedy, Influence of vine vigor on grape (Vitis vinifera L. Cv. Pinot Noir) and wine proanthocyanidins, J. Agric. Food Chem. 53 (2005) 5798-5808.

[6] N. Kontoudakis, M. Esteruelas, F. Fort, J.M. Canals, V. De Freitas, F. Zamora, Influence of the heterogeneity of grape phenolic maturity on wine composition and quality, Food Chem. 124 (2011) 767-774.

[7] R. Mira de Orduña, Climate change associated effects on grape and wine quality and production, Food Res. Int. 43 (2010) 1844-1855.

[8] B. Coombe, The regulation of set and developmento of the grape berry, Acta Hortic. 34 (1973) 261-273.

[9] J.A. Kennedy, M.A. Matthews, A.L. Waterhouse, Changes in grape seed polyphenols during fruit ripening, Phytochemistry 55 (2000) 77-85.

[10] R. Ristic, P.G. Iland, Relationships between seed and berry development of Vitis vinifera L. cv Shiraz: Developmental changes in seed morphology and phenolic composition, Aust. J. Grape Wine Res. 11 (2005) 43-58.

[11] R. Ferrer-Gallego, M. García-Marino, J.M. Hernández-Hierro, J.C. Rivas-Gonzalo, M.T. Escribano-Bailón, Statistical correlation between flavanolic composition, colour and sensorial parameters in grape seed during ripening, Anal. Chim. Acta 660 (2010) 22-28.

[12] M.T. Escribano-Bailón, C. Santos-Buelga, Anthocyanin copigmentation - evaluation, mechanisms and implications for the colour of red wines, Curr. Org.
Chem. 16 (2012) 715-723.

[13] V. de Freitas, N. Mateus, Chemical transformations of anthocyanins yielding a variety of colours (Review), Environ. Chem. Lett. 4 (2006) 175-183.

[14] M.O. Downey, J.S. Harvey, S.P. Robinson, Analysis of Tannins in Seeds and Skins of Shiraz Grapes Throughout Berry Development, Aust. J. Grape Wine Res. 9 (2003) 15-27.

[15] V. Cheynier, C. Prieur, S. Guyot, J. Rigaud, M. Moutounet, The structures of tannins in grapes and wines and their interactions with proteins, Wine: Nutr. Ther. Benefits 661 (1997) 81-93.

[16] A. Gowen, C. O'Donnell, P. Cullen, G. Downey, J. Frias, Hyperspectral imaging an emerging process analytical tool for food quality and safety control, Trends, Food Sci. Technol. 18 (2007) 590-598.

[17] J. Nogales Bueno, F.J. Rodríguez Pulido, B. Baca Bocanegra, M.L. González Miret, F.J. Heredia, J.M. Hernández Hierro, Hyperspectral imaging-a novel green chemistry technology for the oenological and viticultural sectors In: N. Publishers (Ed.), Agricultural Research Updates, New York, USA, 2015.

[18] B. Gordillo, F.J. Rodríguez-Pulido, N. Mateus, M.L. Escudero-Gilete, M. L. González-Miret, F.J. Heredia, V. de Freitas, Application of LC-MS and tristimulus colorimetry to assess the ageing aptitude of Syrah wine in the Condado de Huelva D.O. (Spain), a typical warm climate region, Anal. Chim. Acta 732 (2012) 162-171.

[19] F.J. Rodríguez-Pulido, J.M. Hernández-Hierro, J. Nogales-Bueno, B. Gordillo, M. L. González-Miret, F.J. Heredia, A novel method for evaluating flavanols in grape seeds by near infrared hyperspectral imaging, Talanta 122 (2014) $145-150$.

[20] J.L. Vicente-Villardón, MULTBIPLOT: Multivariate Analysis using Biplots, Departamento de Estadística, Universidad de Salamanca, Salamanca (Spain), 2013.

[21] N. Quijada-Morín, J. Regueiro, J. Simal-Gándara, E. Tomás, J.C. Rivas-Gonzalo, M.T. Escribano-Bailón, Relationship between the sensory-determined astringency and the flavanolic composition of red wines, J. Agric. Food Chem. 60 (2012) 12355-12361.

[22] J.S. Shenk, M.O. Westerhaus, Routine Operation, Calibration, Development and Network System Management Manual, NIR Systems, Silver Spring, MD, USA, 1995.

[23] F.J. Rodríguez-Pulido, J. Nogales-Bueno, J.M. Hernández-Hierro, M.L. GonzálezMiret, F.J. Heredia, Application of tristimulus colorimetry by image analysis to the modeling of the rate of ripeness in grape seeds for winemaking, in: Á. García Codoñer (Ed.), X Congreso Nacional DE Color Valencia (Spain), 2013, pp. 654-659.

[24] J.A. Kennedy, G.P. Jones, Analysis of proanthocyanidin cleavage products following acid-catalysis in the presence of excess phloroglucinol, J. Agric. Food Chem. 49 (2001) 1740-1746.

[25] E. Obreque-Slier, A. Peña-Neira, R. López-Solis, F. Zamora-Marín, J.M. Ricardoda-Silva, O. Laureano, Comparative Study of the Phenolic Composition of Seeds and Skins from Carmenere and Cabernet Sauvignon Grape Varieties (Vitis vinifera L.) during Ripening, J. Agric. Food Chem. 58 (2010) 3591-3599.

[26] M. Bordiga, F. Travaglia, M. Locatelli, J.D. Coisson, M. Arlorio, Characterisation of polymeric skin and seed proanthocyanidins during ripening in six Vitis vinifera L. cv, Food Chem. 127 (2011) 180-187.

[27] M. Monagas, C. Gómez-Cordovés, B. Bartolomé, O. Laureano, J.M. Ricardo-DaSilva, Monomeric, oligomeric, and polymeric flavan-3-ol composition of wines and grapes from Vitis vinifera L. cv. Graciano, Tempranillo, and Cabernet Sauvignon, J. Agric. Food Chem. 51 (2003) 6475-6481.

[28] A. Hernández-Jiménez, E. Gómez-Plaza, A. Martínez-Cutillas, J.A. Kennedy, Grape skin and seed proanthocyanidins from monastrell x syrah grapes, J. Agric. Food Chem. 57 (2009) 10798-10803.

[29] A.B. Bautista-Ortín, P. Rodríguez-Rodríguez, R. Gil-Muñoz, E. Jiménez-Pascual, N. Busse-Valverde, A. Martínez-Cutillas, J.M. López-Roca, E. Gómez-Plaza, Influence of berry ripeness on concentration, qualitative composition and extractability of grape seed tannins, Aust. J. Grape Wine Res. 18 (2012) 123-130. 